\title{
An Investigation of L2 Learners' Writing Self-Efficacy, Writing Anxiety and Its Causes at Higher Education in Turkey
}

\author{
Assist. Prof. Özkan Kırmızı1 \& Gülin Dağdeviren Kırmızı \\ ${ }^{1}$ Karabük University, Turkey \\ ${ }^{2}$ Başkent University, Turkey \\ Correspondence: Assist. Prof. Özkan Kırmızı, Karabük University, Turkey. E-mail: ozkankirmizi@gmail.com
}

Received: February 9, 2015

Accepted: February 26, $2015 \quad$ Online Published: February 27, 2015

doi:10.5430/ijhe.v4n2p57

URL: http://dx.doi.org/10.5430/ijhe.v4n2p57

\begin{abstract}
The present study aimed at investigating higher education L2 learners in a Turkish context in terms of writing self-efficacy, writing anxiety, and the causes of writing anxiety. The data have been collected through the Second Language Writing Anxiety Inventory (SLWAI), developed by Cheng, (2004), and Causes of Writing Anxiety Inventory (CWAI), and Writing Efficacy Scale (WES), developed by Yavuz-Erkan (2004). The participants of the study are 172 English Language and Literature students enrolled in a Turkish state university. Descriptive, variance and correlation analyses were conducted in order to analyze the data. The results indicate that the participants have a moderate level of writing self-efficacy in terms of content, accuracy, design and unity sub-components of writing self-efficacy and have a high level of efficacy in punctuation. In relation to writing anxiety, the participants were found to have a moderate level of writing anxiety. The results of the study suggest that male students have higher levels of writing self-efficacy and they suffer less from writing anxiety. The study also indicated that the major causes of writing anxiety on the part of Turkish L2 learners were time pressure and negative evaluation of the teacher. Finally, correlation analysis indicated that there is a strong negative correlation between writing self-efficacy and writing anxiety.
\end{abstract}

Keywords: Writing self-efficacy, Writing anxiety, Turkish L2 learners

\section{Introduction}

Due to the fact that academic writing requires high mental processes in content, organization of thoughts and structure and use of appropriate grammar and mechanics, it necessitates strong critical thinking skills. Now that writing is a productive skill, students are likely to face a number of obstacles (Erkan \& Saban, 2011). The intricate nature of the writing skill ascends the anxiety level of the students. The ensuing anxiety gives rise to de-motivation and discouragement on the part of the students and as a result they may develop negative attitudes towards writing (Gere, 1987). Recently, researchers became interested in writing anxiety (Atay \& Kurt, 2007; Cheng, Horwitz, and Schallert, 1999; Cheng, 2004, Hassan 2001).

Learners' inadequacy in the writing skill mostly stems from anxiety, which has long been recognized as a barrier in second language learning context for teachers and students. Anxiety in the second language is defined as "the feeling of tension and apprehension specially associated with second language contexts, including speaking, listening, and writing" (MacIntyre \& Gardner, 1991, p. 284). As far as the type of anxiety is concerned, a three-dimensional conceptualization of anxiety was offered by Cheng (2004): (1) somatic anxiety, (2) cognitive anxiety, and (3) avoidance behaviour. Somatic anxiety can be defined as one's perception of the physiological effects of the anxiety experience. It is generally viewed as related to an increase in the state of unpleasant feelings, like nervousness and tension (Cheng, 2004). These types of writing anxiety signify the physiological, cognitive aspects and the effects of writing anxiety on writing processes and behaviors.

Hassan (2001, p. 4) defines second language writing anxiety as "a general avoidance of writing and of situations perceived by the individuals to potentially require some amount of writing accompanied by the potential for evaluation of that writing". Likewise, Daly (1978) also believes that writing anxiety is a situation in which a learner avoids the task of writing in the second language on account of the fact that writing necessitates some amount of formal evaluation by the teacher. In a similar vein, Bloom (1981, p. 104) defines second language writing anxiety as "highly situation specific, seems to be self-limiting, is relatively visible, and more importantly appears to be 
relatively easily overcome by rational instruction". Common to all the definitions given above is that fact that there are negative feelings of anxiety that keep learner from writing in the second language.

Recently, there have been a moderate number of studies that focus on writing anxiety. It has been found that writing anxiety decreases students' performance (Rezaei, Jafari, and Younas, 2014). Daly (1978), for example, discovered that increased writing anxiety leads to insufficient messages like shorter and simpler structures in students' writing assignments. According to Hassan (2001), students with low anxiety came up with better quality compositions compared to students with high anxiety. Likewise, Cheng's (2002) study also confirmed previous findings. The study found that students with high level of anxiety are reluctant to take writing courses. There are also a number of studies that indicated that writing apprehension has a negative influence on EFL/ESL learners' writing performance and quality (Cheng, Horwitz \& Shallert, 1999; Atay \& Kurt, 2007). Naghaded et at. (2014) worked on the relation between writing anxiety and narrative proficiency and found that writing anxiety hinders the ability of narrative proficiency. In a more recent study, Jebreil et al. (2015) found that prospective Iranian EFL teachers experienced a high level of anxiety. Students with elementary level were also found to suffer higher level of English writing anxiety than the students with intermediate and advanced levels. The study also indicated that the most common type of anxiety was cognitive anxiety, followed by somatic anxiety, and avoidance behavior.

In a subsequent study, Cheng (2004) devised the writing anxiety scale entitled Second Language Writing Anxiety Inventory (SLWAI). This inventory was used in the present study since it includes the sub-categories that the study aims to investigate. These sub-categories are cognitive anxiety, avoidance behavior, and somatic anxiety. Salem and Al Dyiar (2014) investigated writing anxiety in relation to writing self-efficacy and found that the relation between writing anxiety and writing self-efficacy was more pervasive with male students. As for the causes of writing anxiety, Abdel-Latif (2007) iterated the factors that lead to Egyptian English major students writing anxiety and low writing self-efficacy. From his summary, six factors emerged and they were lack of linguistic knowledge, low foreign language competence, low self-esteem, poor history of writing achievement, and fear of criticism.

Due to its complicated nature, the writing skill poses problems on the part of L2 learners and writers who can convey their messages effectively to the receiver through proper grammatical structures and vocabulary items are called proficient writers (Graham, Harris, \& Mason, 2005). However, there are a number of factors that may have serious effects on L2 learners writing ability. These are lack of confidence, low self-efficacy and motivation (Sawyer, Graham \& Harris, 1992). It is generally believed that learners who have a satisfactory level of writing self-efficacy perceive themselves as good writers and they can pursue writing opportunities and can spare more energy to their writing process (Bottomley, Henk, \& Melnick, 1997). Thus, a high perception of writing self-efficacy is crucial for the development of the writing skill.

Bandura (1995, p.2) defines self-efficacy as "the belief in one's capabilities to organize and execute the courses of action required to manage prospective situations." It refers to students' beliefs as regards their ability to perform a particular task and it is considered among the expectancy components of motivation (Pintrich \& De Groot, 1990). Students with a high level of self-efficacy have a high level of self-confidence and they believe that they can organize the learning environment in a way conducive to their own learning (Bandura, 1986). Therefore, writing self-efficacy would imply a high sense of efficacy and confidence for the task of writing. L2 learners are expected to have writing self-efficacy in terms of content, design, unity, and accuracy, punctuation.

There is no doubt that one of the indispensible factors in ensuring the development of the writing skill on the part of L2 learners is motivation and encouragement (Fatemi \& Vahidnia, 2013). It is almost imperative in the teaching of the writing skill to ensure the cognitive, behavioral and motivational engagement of students, which is facilitated by increased writing self-efficacy. Writing self-efficacy can be defined as the individual's perception and evaluation of his or her writing skills (McCarthy, Meier, \& Rinderer, 1985). Another definition of writing self-efficacy can be a student's "belief in his or her ability to successfully perform writing tasks at a given level" (Shell, Murphy, \& Bruning, 1989). Students with a high level of writing self-efficacy possess strong confidence in writing ability. Those who have a reduced or low level of writing self-efficacy do not have sufficient confidence in the writing skill. Therefore, individual with high level of writing self-efficacy view difficult writing tasks a challenge and work accordingly to resolve the problems that they face (Lavelle, 2006).

As we can understand, writing anxiety has been studied to a moderate level in the literature and similarly there are few research studies that focus on writing anxiety. However, there is a lack of studies that focus on the writing self-efficacy and writing anxiety levels of Turkish EFL learners. In addition, there are no studies in the Turkish context that dwell on writing self-efficacy and writing anxiety. Therefore, the present study aims at investigating the 
writing self-efficacy and writing anxiety levels of Turkish EFL learners and to determine the relation between writing self-efficacy and writing anxiety. Thus, the present study aims at answering the following research questions:

1. What is the level of writing self-efficacy for Turkish EFL university students?

2. What is the level of writing anxiety for Turkish EFL university students and what are its perceived causes?

3. Do male and female Turkish EFL university students differ in terms of their perceived writing self-efficacy and writing anxiety?

4. What is the correlation between writing self-efficacy and writing anxiety?

5. Do higher education students differ in terms of their perceived writing self-efficacy and writing self-efficacy based on their grade?

\section{Method}

\subsection{Participants}

The participants in the present study are 172 English Language and Literature department students. The number of female students is $130(75.6 \%)$, and the number of male students is $42(24.4 \%)$. In terms of grades (year of study), 96 $(55.8 \%)$ of the participants are second grade students, $52(30.2 \%)$ of the students are third grade students, and 24 $(14.0 \%)$ of them are fourth grade students. All groups of students are exposed to the same teaching program.

\subsection{Data Collection Tools}

Two questionnaires were used in the present study. The first was Second Language Writing Anxiety Inventory (SLWAI) which contains 22 items. It was developed by Cheng (2004) in order to measure the level anxiety of student writers experience when writing in English. SLWAI consists of three sub-dimensions: somatic anxiety (as reflected in negative feelings such as tension), cognitive anxiety (as reflected in negative expectations, preoccupation with performance), and avoidance behavior (as reflected in avoidance in writing). SLWAI was selected as a data collection tool on account of the fact that it has been proved as being highly reliable and valid by means of correlation and factor analysis (Cheng, 2004). The questionnaire has a Likert-type 5-choice response format: 1 (strongly disagree), 2 (disagree), 3 (undecided), 4 (agree), and 5 (strongly agree). The distribution of items across three subcategories is as follows: (1) cognitive anxiety $(1,3,7,9,14,17,20,21),(2)$ somatic anxiety $(2,6,8,11,13,15,19)$, and (3) avoidance behavior $(4,5,10,12,16,18,22)$. The questionnaire was administered in English because the subjects are English Language and Literature students. Unclear points were explained during the administration process. The Cronbach's Alpha of the Inventory was 0.89 , which was within acceptable range of reliability. Cronbach's Alpha values higher than 0.60 are viewed as acceptable in social sciences.

The self-efficacy scale developed by Yavuz-Erkan (2004) was used to assess the students' self-efficacy in writing. Based on the self-efficacy construct proposed by Bandura (1977), Yavuz-Erkan developed a 21 -item writing self-efficacy scale to grade the strength of subjects' beliefs in their writing ability. The items of the scale were graded with the four-tier system Likert scale: (1) strongly disagree, (2) disagree, (3) undecided, (4) agree, and (5) strongly agree. The reliability and validity analyses were calculated by Yavuz-Erkan (2004). The Cronbach's alfa coefficients were .88 for the first factor (Content), .80 for the second factor (Design), .77 for the third factor (Unity), .74 for the fourth factor (Accuracy), and .50 for the fifth factor (Punctuation).

In order to identify the causes of writing anxiety, a 10-item questionnaire called Causes of Writing Anxiety Inventory (CWAI) was developed on the basis of possible causes of anxiety ranging from lack of proper practice to lack of sufficient grammar competence.

\subsection{Data Analysis}

The study initially employs descriptive statistics in order to measure the writing self-efficacy and writing anxiety levels of higher education EFL learners. Subsequently, in order to investigate whether writing self-efficacy and writing anxiety levels differ in terms of gender, a T-test was run. Finally, in order to find out the correlation between writing self-efficacy and writing anxiety, correlation analysis was carried out.

\section{Results}

Research question 1: What is the level of among Turkish EFL university students' writing self-efficacy?

The initial aim of the study was to determine the level of Turkish higher education EFL learners' writing self-efficacy. Table 1 presents the descriptive statistics about writing self-efficacy. In order to analyze EFL learners' writing self-efficacy with its sub-dimensions, the results of 172 participants were grouped as low, medium, and high. 
To do this, the maximum values were divided into three in order to find the cut-off points. The cut-off points for the variables are as follows: content (low=1-7, medium=7-14, high=14-20), design (low=1-8, medium=8-17, high=17-25), unity (low=1-8, medium=8-17, high=17-25), accuracy (low=1-7, medium=7-14, high=14-20) and punctuation (low $=1-3$, medium=3-7, high=7-10). The results are presented in Table 1 . The table shows that the participants have a medium level of writing efficacy in terms of content, design, unity, and accuracy and they have a high level of writing self-efficacy in terms of punctuation.

Table 1. Descriptive statistics about writing self-efficacy

\begin{tabular}{lllllll}
\hline Sub-components of writing self-efficacy & \multicolumn{2}{l}{ Low } & \multicolumn{3}{l}{ Medium } & \multicolumn{3}{l}{ High } \\
\cline { 2 - 7 } & $f$ & $\%$ & $f$ & $\%$ & $f$ & $\%$ \\
\hline Content & 6 & 3.50 & 159 & $\mathbf{9 2 . 9 8}$ & 12 & $\mathbf{7 . 0 1}$ \\
Design & 1 & 0.58 & 107 & $\mathbf{6 2 . 5 7}$ & 63 & 36.84 \\
Unity & 1 & 0.58 & 89 & $\mathbf{5 2 . 0 4}$ & 81 & 47.36 \\
Accuracy & 0 & 0 & 86 & $\mathbf{5 0 . 2 9}$ & 85 & 49.70 \\
Punctuation & 1 & 0.58 & 69 & 40.35 & 101 & $\mathbf{5 9 . 0 6}$
\end{tabular}

Research question 2: What is the level of writing anxiety among Turkish EFL university students and what are its perceived causes?

The second primary aim of the presents study was to measure the writing anxiety level of Turkish English Language and Literature Department students. In order to do this, the results of 172 participants were grouped as low, medium, and high. To do this, the maximum values were divided into three in order to find the cut-off points. The cut-off points for the variables are as follows: cognitive anxiety (low=1-13, medium=13-26, high=26-40), somatic anxiety $($ low $=1-12$, medium=12-24, high=24-35), and avoidance behavior unity (low=1-12, medium=13-26, high=26-40). The results are presented in Table 1. The table also indicates that the participants have a medium level of cognitive anxiety (58.47\%). As for somatic anxiety, almost half of the participants have a moderate level of somatic anxiety $(48.53 \%)$ and the other half has a high level of somatic anxiety (48.53\%). Finally, as we can understand from Table 2, Turkish English Language and Literature department students have a medium level of avoidance behavior.

Table 2. Descriptive statistics about sub-components of writing anxiety

\begin{tabular}{lllllll}
\hline Sub-components of writing anxiety & \multicolumn{2}{l}{ Low } & \multicolumn{3}{l}{ Medium } & \multicolumn{3}{l}{ High } \\
\cline { 2 - 7 } & $f$ & $\%$ & $f$ & $\%$ & $f$ & $\%$ \\
\hline Cognitive anxiety & 0 & 0 & 100 & $\mathbf{5 8 . 4 7}$ & 71 & 41.52 \\
Somatic anxiety & 5 & 2.92 & 83 & $\mathbf{4 8 . 5 3}$ & 83 & $\mathbf{4 8 . 5 3}$ \\
Avoidance behavior & 3 & 1.75 & 132 & $\mathbf{7 7 . 1 9}$ & 36 & 21.05 \\
\hline
\end{tabular}

Table 3 presents the results regarding the causes of writing anxiety. As we can understand from the table, the most important cause of writing anxiety is time pressure $(\mathrm{M}=3.8779)$. The second most important cause of writing anxiety is negative evaluation of the teacher $(\mathrm{M}=3.6512)$, and it is followed by lack of sufficient English writing practice $(\mathrm{M}=3.4942)$. The fourth cause of writing anxiety is pressure for perfect work $(\mathrm{M}=3.4826)$ and it is followed by linguistic problems $(\mathrm{M}=3.4477)$. Another important cause of writing anxiety is frequency of writing assignments $(\mathrm{M}=3.2674)$ and the following one is insufficient writing practice $(\mathrm{M}=3.1860)$. Problems with topic selection seems to be moderately influential on writing anxiety $(\mathrm{M}=3,0058)$. The last two causes of writing anxiety are low self-confidence in English writing $(\mathrm{M}=2.8256)$ and fear of writing tests $(\mathrm{M}=2.7849)$. As we can understand from the results, the most serious causes of writing anxiety among English language and literature department students are time pressure, negative evaluation of the teacher, and lack of sufficient English writing practice. 
Table 3. Descriptive statistics about the causes of writing anxiety

\begin{tabular}{llllll}
\hline Causes of Second Language Writing Anxiety Inventory & $\mathbf{N}$ & Min. & Max. & M & sd \\
\hline 1. $\quad$ negative evaluation of the teacher. & 171 & 1.00 & 5.00 & 3.6512 & 1.12148 \\
2. $\quad$ fear of writing tests. & 171 & 1.00 & 5.00 & 2.7849 & 1.12661 \\
3. lack of sufficient English writing practice & 171 & 1.00 & 5.00 & 3.4942 & 1.10022 \\
4. insufficient writing practice & 171 & 1.00 & 5.00 & 3.1860 & 1.06526 \\
5. problems with topic selection & 171 & 1.00 & 5.00 & 3.0058 & 1.19696 \\
6. linguistic problems & 171 & 1.00 & 5.00 & 3.4477 & 1.15097 \\
7. $\quad$ pressure for perfect work & 171 & 1.00 & 5.00 & 3.4826 & .98214 \\
8. $\quad$ frequency of writing assignments. & 171 & 1.00 & 5.00 & 3.2674 & .96639 \\
9. $\quad$ time pressure. & 171 & 1.00 & 5.00 & 3.8779 & .99835 \\
10. low-confidence in English writing & 171 & 1.00 & 5.00 & 2.8256 & 1.14649 \\
\hline
\end{tabular}

Research question 3: Do male and female Turkish EFL university students differ in terms of their perceived writing self-efficacy and writing anxiety?

In order to determine whether there are differences between male and female students in terms of their perceived writing self-efficacy, a T-test was carried out. The results are presented in Table 4 . When we examine the table, we can see that there are no statistically significant differences between male and female students in terms of content and punctuation items $(\mathrm{p}>.05)$. However, statistically significant differences were found between male and female students in terms of design, unity, and accuracy sub-components $(\mathrm{p}<.05)$. As for design sub-component, we can understand from the table that male students rank higher than their female counterparts in terms of design sub-component (male=16.9048, female=15.5615), unity sub-component (male=17.1190, female=16.0231), and accuracy (male $=14.6429$, female $=12.9231$ ). It is clearly seen that male students in the present study seem to have higher level of writing self-efficacy.

Table 4. T-test results for writing self-efficacy in relation to gender

\begin{tabular}{llllll}
\hline Writing self-efficacy & Gender & $\mathbf{N}$ & $\mathbf{M}$ & $\mathbf{F}$ & Sig. \\
\hline Content & female & 130 & 12.6615 & 1.877 & .184 \\
& male & 42 & 13.3333 & & \\
Design & female & 130 & 15.5615 & 2.634 & $\mathbf{. 0 1 1}$ \\
Unity & male & 42 & 16.9048 & & \\
Accuracy & female & 130 & 16.0231 & .769 & $\mathbf{. 0 3 6}$ \\
& male & 42 & 17.1190 & & \\
Punctuation & female & 130 & 12.9231 & .499 & $\mathbf{. 0 0 0}$ \\
& male & 42 & 14.6429 & & \\
Writing self-efficacy total & female & 130 & 6.7308 & 1.285 & .120 \\
& male & 42 & 7.1429 & & \\
& female & 130 & 63.9000 & .002 & $\mathbf{. 0 0 5}$
\end{tabular}

Table 5 presents the results of the T-test that was carried out in order to compare male and female students in terms of writing anxiety and its sub-components. As we can understand from the table, there are no statistically significant differences between male and female students in terms of cognitive anxiety ( $p>05)$, avoidance behavior ( $p>05)$, and writing anxiety in general $(\mathrm{p}>.05)$. However, a statistically significant difference was observed between male and female students in terms of somatic anxiety $(\mathrm{p}<.05)$. Female participants seem to suffer more from somatic anxiety. 
Table 5. T-test results for writing anxiety in relation to gender

\begin{tabular}{llllll}
\hline Writing anxiety & Gender & $\mathbf{N}$ & $\mathbf{M}$ & $\mathbf{F}$ & Sig. \\
\hline Cognitive anxiety & female & 130 & 24.5154 & 2.947 & .469 \\
& male & 42 & 24.9286 & & \\
Somatic anxiety & female & 130 & 23.7615 & .082 & $\mathbf{. 0 0 3}$ \\
Avoidance behavior & male & 42 & 20.9286 & & \\
Writing anxiety total & female & 130 & 20.3231 & .521 & .625 \\
& male & 42 & 20.0000 & & \\
& female & 130 & 68.6000 & .285 & .077 \\
\hline
\end{tabular}

Research question 4: Do students from different grade levels differ in terms of their perceived writing self-efficacy and writing anxiety?

In order to understand whether there are statistically significant differences between grade levels in terms of writing self-efficacy and writing anxiety, an ANOVA was conducted. The results are presented in Table 6. the sub-components of writing self-efficacy are content, design, unity, accuracy, and punctuation while the sub-components of writing anxiety are cognitive anxiety, somatic anxiety, and avoidance behavior. As we can understand from the Table $\mathrm{X}$, there are no statistically significant differences among students from different grade levels in terms of content $(\mathrm{p}>.05)$, design sub-component $(\mathrm{p}>.05)$, and accuracy sub-components $(\mathrm{p}>.05)$. However, as regards writing self-efficacy statistically significant differences were observed in terms of unity and punctuation sub-components $(\mathrm{p}<.05)$. We can understand from the mean scores that third grade students have a lower level of unity $(\mathrm{M}=15.307)$. As for the punctuation sub-component, it is obvious from the table that fourth grade students have higher levels of competence $(\mathrm{M}=7.6250)$. As for the low level of unity on the part of third grade students, it can be speculated that now that they have a "research methods" course in which they have to write an academic term paper that complies with the entire requirements, they may have a lowered level of confidence in unity.

When it comes to writing anxiety, Table $\mathrm{X}$ indicates that there are no statistically significant differences between different grade levels in terms of cognitive anxiety $(\mathrm{p}>.05)$. However, there are statistically significant difference among grade levels in terms of somatic anxiety $(\mathrm{p}<.05)$ and avoidance behavior $(\mathrm{p}<.05)$. Interestingly, third grade students suffer more from somatic anxiety compared to second and fourth grade students. This can be linked to the fact again that they have a research course and this may be the main cause of somatic anxiety. 
Table 6. ANOVA results for grade levels and writing self-efficacy and writing anxiety.

\begin{tabular}{|c|c|c|c|c|c|}
\hline Variables & status & $\mathbf{N}$ & M & $\mathbf{F}$ & Sig. \\
\hline \multirow[t]{3}{*}{ Content } & 2. grade & 96 & 13.2604 & 3.019 & .052 \\
\hline & 3. grade & 52 & 12.0769 & & \\
\hline & 4. grade & 24 & 12.7083 & & \\
\hline \multirow[t]{3}{*}{ Design } & 2. grade & 96 & 16.1146 & 1.562 & .213 \\
\hline & 3. grade & 52 & 15.2885 & & \\
\hline & 4. grade & 24 & 16.2917 & & \\
\hline \multirow[t]{3}{*}{ Unity } & 2. grade & 96 & 16.8021 & 4.507 & .012 \\
\hline & 3. grade & 52 & 15.3077 & & \\
\hline & 4. grade & 24 & 16.3750 & & \\
\hline \multirow[t]{3}{*}{ Accuracy } & 2. grade & 96 & 13.1250 & 2.317 & .102 \\
\hline & 3. grade & 52 & 13.2885 & & \\
\hline & 4. grade & 24 & 14.3333 & & \\
\hline \multirow[t]{3}{*}{ Punctuation } & 2. grade & 96 & 6.7708 & 4.405 & .014 \\
\hline & 3. grade & 52 & 6.5769 & & \\
\hline & 4. grade & 24 & 7.6250 & & \\
\hline \multirow[t]{3}{*}{ Cognitive anxiety } & 2. grade & 96 & 24.6146 & .346 & .708 \\
\hline & 3. grade & 52 & 24.8269 & & \\
\hline & 4. grade & 24 & 24.1667 & & \\
\hline \multirow[t]{3}{*}{ Somatic anxiety } & 2. grade & 96 & 23.1979 & 3.884 & .022 \\
\hline & 3. grade & 52 & 24.0577 & & \\
\hline & 4. grade & 24 & 20.4167 & & \\
\hline \multirow[t]{3}{*}{ Avoidance behavior } & 2. grade & 96 & 20.3021 & 3.902 & .022 \\
\hline & 3. grade & 52 & 20.9615 & & \\
\hline & 4. grade & 24 & 18.4583 & & \\
\hline
\end{tabular}

Table 7 gives the ANOVA results regarding the total level of writing self-efficacy and writing anxiety and grade level. The results indicate that there are no statistically significant differences between students from different grades in terms of writing self-efficacy. However, as that table indicates, the participants differ significantly in terms of writing anxiety. Interestingly, third grade students seem to suffer more from writing anxiety. as was stated previously, it can possibly be attributed to the fact that third grade students have to write "terms papers" that comply with all the requirements of an academic paper as a pre-requisite of the course entitled "Research Techniques".

Table 7. ANOVA results for grade levels and writing self-efficacy and writing anxiety

\begin{tabular}{llllll}
\hline Variables & status & N & M & F & Sig. \\
\hline Writing self-efficacy total & 2. grade & 96 & 66.0729 & 2.738 & .068 \\
& 3. grade & 52 & 62.5385 & & \\
\multirow{3}{*}{ Writing anxiety total } & 4. grade & 24 & 67.3333 & & \\
& 2. grade & 96 & 68.1146 & 5.279 & $\mathbf{. 0 0 6}$ \\
& 3. grade & 52 & 69.8462 & & \\
& 4. grade & 24 & 63.0417 & & \\
\hline
\end{tabular}

Research question 4: What is the correlation between writing self-efficacy and writing anxiety?

In order to measure the correlation between writing self-efficacy and writing anxiety, a correlation analysis was carried out. The results are presented in Table 8. As can be seen from the table, there were high positive relationships 
between the sub-dimensions of writing self-efficacy: content and design $(r=.68, p<.01)$, content and unity $(r=.64$, $p<.01)$, content and accuracy $(r=.31, p<.01)$, and content and punctuation $(r=.38, p<.01)$. This was already the expected result. When it comes to the correlation between anxiety and the sub-dimensions of writing self-efficacy, we can see that there are negative correlations between writing self-efficacy and writing anxiety. The highest negative correlation occurred between anxiety and design sub-component of writing self-efficacy $(r=.-34, p<.01)$,a moderate level of negative correlation was found between anxiety and accuracy $(r=.-27, p<.01)$, and punctuation $(r$ $=.-27, p<.01)$. The results clarify that there is a negative correlation between writing self-efficacy and writing anxiety. That is to say, as anxiety decreases writing self-efficacy increases.

Table 8. Pearson correlations among the variables of the study

\begin{tabular}{|c|c|c|c|c|c|c|}
\hline variables & content & design & unity & accuracy & punc & anxiety \\
\hline content & &, $68^{* *}$ &, $64 * *$ &, $31 * *$ &, $38 * *$ &,$- 19^{*}$ \\
\hline design & & &, $72 * *$ &, $46^{* *}$ &, $46^{* *}$ &,$- 34 * *$ \\
\hline unity & & & &, $48^{* *}$ &, $43^{* *}$ &,$- 33 * *$ \\
\hline accuracy & & & & &, $58 * *$ &,$- 27 * *$ \\
\hline punctuation & & & & & &,$- 27 * *$ \\
\hline anxiety & & & & & & \\
\hline
\end{tabular}

\section{Discussion}

The primary aim of the present study was to measure the writing self-efficacy and writing anxiety levels of Turkish English Language and Literature department students. As for writing self-efficacy, the present study found that the participants have a moderate level of efficacy in terms of content, design, unity, and accuracy sub-dimensions and they have a high level of writing self-efficacy in terms of punctuation sub-dimension. Therefore, we can say that Turkish EFL students have a moderate level of writing self-efficacy. As for writing anxiety, the study found that the participants have a medium level of cognitive anxiety and somatic anxiety. This finding supports Atay and Kurt's (2007) study which focused on the writing anxiety of prospective EFL teachers in Turkey and found that the majority of the Turkish prospective English teachers had average to high level of writing anxiety. Finally, Turkish English Language and Literature department students were found to have a considerably medium level of avoidance behavior. The study also undertook to investigate the causes of writing anxiety. The results indicated the students rated time pressure, negative evaluation of the teacher, and lack of sufficient English writing practice as the most important causes of writing anxiety.

In relation to the influence of gender in writing self-efficacy and writing anxiety, the study found statistically significant differences between male and female students. According to the results of the study, male students ranked higher than female students in terms of design, unity, and accuracy sub-components. There are controversial results in literature as regard the role of gender writing anxiety. The common belief is that male students suffer more anxiety compared to male counterparts. A number of studies found female students have relatively lower levels of writing anxiety (Al-Asmari, 2013). However, there is also a line of research that suggests that female students suffer more anxiety. Pappamihiel (2002), for example, found that females were much more anxious than males in the mainstream classroom. The results of the present study also found that although there are no differences between male and female students in relation to writing anxiety in general, female students were found to suffer more from somatic anxiety.

Another aim of the study was to compare students from different grade levels in terms of writing self-efficacy and writing anxiety. The results indicated that there are no statistically significant differences in terms of content, design, and accuracy. However, statistically significant differences were observed in terms of unity and punctuation. As for punctuation, third grade students have the lowest level of self-efficacy beliefs. It was speculated that their self-efficacy beliefs may have been lowered by the fact that they have to write a research paper in this term, which is a demanding task for them. This might have lowered their writing self-efficacy in unity. As for writing anxiety, the variance analysis demonstrated that there are no statistically significant differences among grade levels in terms of cognitive anxiety. However, the participants were observed to differ statistically in terms of somatic anxiety and avoidance behavior. Third grade students seem to suffer more from somatic anxiety and second and third grade student tend to avoid the writing task compared to fourth grade students. 
Another important aim of the study was to determine the correlation between writing anxiety and writing self-efficacy. It is already expected that there should be a negative correlation. The results confirmed this expectation. The study produced the results that there were strong negative correlation between writing self-efficacy and writing anxiety. That is to say, students writing self- efficacy increases as their anxiety decrease. Therefore, language teachers must do their best to lower their students' writing anxiety.

\section{Conclusion}

Some researchers found that the Mastery Model contributed to the development of writing self-efficacy compared to no-model method (Zimmerman \& Kitsantas, 2002). Research also indicates that feedback was found to positively correlate with writing self-efficacy. Therefore, future studies on writing self-efficacy can focus on the role of various models or various feedback methods in Turkish context.

The present study found that English Language and Literature department students have moderate to high level of anxiety. This finding was also voiced in other studies that were carried out in Turkey. The negative impact of writing anxiety, writing apprehension, was stated by some researchers (Cheng, Horwitz \& Shallert, 1999; Atay \& Kurt, 2007). Jahin (2012) found that peer feedback reduces writing anxiety to a certain extent. Similarly, Atay and Kurt (2007) also found that peer reviewing has a positive impact on L2 learners' writing anxiety. Therefore, language teachers or instructors at tertiary level should lower their students' writing anxiety by rendering peer reviewing. In addition, more studies can be carried out on other variables that may reduce writing anxiety on the part of students.

Rezaei, Jafari, and Younas (2014) in their study stated that Iranian students did not have an adequate level of writing self-efficacy and they attributed this to a variety of factors including L2 writing instruction, lack of motivation, L2 writing feedback, lack of target language proficiency and vocabulary, the interference of L1 into L2 and psychological variables such as anxiety which is the focus of this study. Similarly, Abdel-Latif (2007) also ascribed low writing self-efficacy and high writing anxiety to factors like lack of sufficient English proficiency, lack of practice in writing, low self-esteem and fear of being assessed. Therefore, future studies on writing self-efficacy can focus on the reasons that cause students to have low level of writing self-efficacy.

\section{References}

Abdel-Latif, M. (2007).The factors accounting for the Egyptian EFL University Students' Negative Writing Affect. Essex Graduate Student Papers in Language\& Linguistics, 9, 57-82.

Al Asmari, A. (2013). Investigation of Writing Strategies, Writing Apprehension, and Writing Achievement among Saudi EFL-Major Students, International Education Studies, 6(11), 130-143.

Atay, D. \& Kurt, G. (2007). Prospective teachers and L2 writing anxiety. Asian EFL Journal, 8(4):100-118.

Bandura, A. (1995). Self-efficacy in changing societies. New York, NY: Cambridge University Press. http://dx.doi.org/10.1017/CBO9780511527692

Bandura, A. (1986). Social foundations of thought and action: A social cognitive view. Eaglewood Cliffs: Prentice Hall.

Bloom, L. (1981). Why graduate students can't write: Implications of research on writing anxiety for graduate education. Journal of Advanced Composition, 2(1-2), 103-117.

Bottomley, D., Henk, W., \& Melnick, S. (1997). Assessing children's views about themselves as writers using the Writer SelfPerception Scale. The Reading Teacher, 51(4), 286-291.

Cheng, Y. S., Horwitz, E. K., \& Schallert, D. (1999). Language anxiety: Differentiating writing and speaking components. Language Learning, 49(3), 417-446. http://dx.doi.org/10.1111/0023-8333.00095

Cheng, Y. S. (2002).Factors associated with foreign language writing anxiety. Foreign Language Annuals, 35(5), 647-56. http://dx.doi.org/10.1111/j.1944-9720.2002.tb01903.x

Cheng, Y. S. (2004). A measure of second language writing anxiety: Scale development and preliminary validation. Journal of Second Language Writing, 13(4), 313-335. http://dx.doi.org/10.1016/j.jslw.2004.07.001

Daly, J. (1978). Writing apprehension and writing competency. Journal of Educational Research, 72, 10-12. http://dx.doi.org/10.1080/00220671.1978.10885110

Erkan, D. Y., \& Saban, A. I. (2011). Writing Performance Relative to Writing Apprehension, Self-Efficacy in Writing, and Attitudes towards Writing: A Correlational Study in Turkish Tertiary-Level EFL. Asian EFL journal, 5(4), 164-192. 
Fatemi, A. H., \& Vahidnia, F. (2013). An Investigation into Iranian EFL Learners' Level of Writing Self-efficacy, Theory and Practice in Language Studies, 3(9), pp. 1698-1704. http://dx.doi.org/10.4304/tpls.3.9.1698-1704

Gere, A. R. (1987). Writing groups: History, theory and implications. Carbondale: Southern Illinois University Press.

Graham, S., Harris, K.R.., \& Mason, L. (2005). Improving the writing performance, knowledge and self-efficacy of struggling young writers: The effects of self-regulated strategy development. Contemporary Educational Psychol., 30, 207-241. http://dx.doi.org/10.1016/j.cedpsych.2004.08.001

Hassan, B. (2001). The Relationship of Writing Apprehension and Self-Esteem to the Writing Quality and Quantity of EFL University Students. Mansoura Faculty of Education Journal, 39, 1-36.

Jahin, J. H. (2012). The effect of peer reviewing on writing apprehension and essay writing ability of prospective EFL teachers, Australian Journal of Teacher Education, 37(11), p. 60-84. http://dx.doi.org/10.14221/ajte.2012v37n11.3

Jebreil, N., Azizifar, A., Gowhary, H. \& Jamalinesari, A. (2015). A Study on Writing Anxiety among Iranian EFL Students, International Journal of Applied Linguistics \& English Literature,4(2) 68-72. http://dx.doi.org/10.7575/aiac.ijalel.v.4n.2p.68

Lavelle, E. (2006). Teachers" self-efficacy for writing. Electronic Journal of Research in Educational Psychology, 8(4-1), 73-84.

McCarthy, P., Meier, S., \& Rinderer, R. (1985). Self-efficacy and writing: A different view of self-evaluation. College Composition and Communication, 36(4), 465-471. http://dx.doi.org/10.2307/357865

MacIntyre, P. \& Gardner, R.C. (1991). Investigating Language Class Anxiety Using the Focused Essay Technique. The Modern Language Journal, 75, pp.296-304. http://dx.doi.org/10.1111/j.1540-4781.1991.tb05358.x

Naghadeh, M.A., Naghadeh, N.A., Kasraey, S., Maghdour, H. \& Kasraie, S. (2014). The relationship between anxiety and Iranian EFL learners' narrative writing performance, International Journal of Psychology and Behavioral Research. 3(6):602-609.

Pappamihiel, N. E. (2002). English as a second language students and English language anxiety: Issues in the mainstream classroom. Research in the Teaching of English, 36, 327-355.

Pintrich, R. R., \& De Groot, E. V. (1990). Motivational and self-regulated learning components of classroom academic performance, .Journal of Educational Psychology, 82, 33-40. http://dx.doi.org/10.1037/0022-0663.82.1.33

Rezaei, M.M., Jafari, S.M. \& Younas, M. (2014). Iranian EFL Students' Writing Anxiety: Levels, Causes and Implications, English for Specific Purposes World, 42(15), 1-10.

Salem, A.A.M.M. \& Al Dyiar, M. A. (2014). Writing Anxiety as a Predictor of Writing Self-Efficacy in English for Special Education Arab Learners, International Education Studies, 7(6), 128-134.

Sawyer, R., Graham. S., \& Harris, K.R. (1992). Direct teaching, strategy instruction, and strategy instruction with explicit selfregulation: Effects on learning disabled students" compositions and self-efficacy. Journal of Educational Psychology, 84, 340- 352. http://dx.doi.org/10.1037/0022-0663.84.3.340

Shell, D. F., Murphy, C. C., \& Bruning, R. H. (1989). Self-efficacy and outcome expectancy mechanisms in reading and writing achievement. Journal of Educational Psychology, 81, 91-100. http://dx.doi.org/10.1037/0022-0663.81.1.91

Yavuz-Erkan, D. (2004). Efficacy of cross-cultural e-mail exchange for enhancing EFL writing: A perspective for tertiary-level Turkish EFL learners. Unpublished Dissertation. Çukurova University, The Institute of Social Sciences English Language Teaching. Adana/Turkey.

Zimmerman, B.J \& Kitsantas, A., (2002). Acquiring writing revision and self-regulatory skill through observation and emulation. Journal of Educational and Psychology, 94, 660-668. 